\title{
Electrolysis: An Innovative Technique to Desaturate Tailings
}

\author{
Sara Grargano and Lucia Mele* \\ Department of Civil, University of Napoli Federico II, Italy
}

Submission: July 12, 2019; Published: August 23, 2019

*Corresponding author: Lucia Mele, Department of Civil, Architectural and Environmental Engineering (DICEA), University of Napoli "Federico II", Napoli, Italy

Abstract

Within the entire range of failure modes that have occurred at tailings impoundments, static and dynamic liquefaction are likely the most common. Static liquefaction can be a result of slope instability issues alone or can be triggered as a result of other mechanisms, dynamic liquefaction may be triggered by rapid forms of cyclic loadings, such as earthquakes. Several techniques, that have the aim to prevent this kind of failure, have been developed during the last centuries. In this paper, the attention will be focused on desaturation and on electrolysis as an innovative technique to desaturate the soils.

Keywords: Tailings; Liquefaction; Desaturation; Electrolysis

\section{Introduction}

Tailings dams are some of the largest earth structures geotechnical engineers construct. After separating the ore from the gangue, the byproduct of mining may be stored to build tailings dams (earth-fill embankment). Generally, tailings can be liquid, solid, or a slurry of fine particles, usually characterized by high toxicity and polluting substances. Owing to that, it is important to treat this kind of materials for a possible reuse or before dumping. The tailings deposits are usually soft, loose and permanently saturated. As a consequence, they may be subjected to liquefaction phenomena. Liquefaction phenomena can be due to monotonic or cyclic loading in undrained conditions. The former is called static liquefaction, while the latter cyclic liquefaction. In both cases, a sudden increase of pore pressure may lead to a loss of shear strength and stiffness with catastrophic consequences.

Several cases of such dam incidents (static and dynamics liquefaction) have been reported recently. Failures of the Barahona dam (Chile) in 1928; El Coble dam (Chile) in 1965; Mochikoshi dam (Japan) in 1978; Merriespruit (South Africa) in 1994; Omai (Guyana) in 1994; Los Frailes (Spain) in 1998; Baia Mare (Romania) in 2000 and Aitik (Sweden) in 2000 are typical examples of failures of the tailings dams. It is worth noting that these critical phenomena involve all parts of the world.

An acute societal concern over such events has resulted in enforcing stringent safety criteria at mining operations in some parts of the globe. However, the standard of public reporting varies considerably from country to country and from region to region. Many tailings dam failure incidents remain unreported or lack basic information when reported. This has seriously hindered the development of safety regulations in such areas. It is extremely important to increase the safety coefficient in these areas. Owing to that, researchers in the world are studying this kind of phenomena to develop new technologies to mitigate their effects as much as possible.

\section{Desaturation as Mitigation Technique Against Liquefaction}

It is important to consider liquefaction potential of dams or embankments to prevent this kind of phenomena. Various techniques have been developed during the last centuries, such as: densification; draining; soil reinforcement and desaturation. One of the most promising techniques against liquefaction is desaturation. As well-known when the degree of saturation (Sr) increases, the resistance to liquefaction increases. Desaturation seems to be a useful remediation against liquefaction, especially in cyclic liquefaction as shown by several research works [14]. In fact, a small decrease in the degree of saturation of a fully saturated sand can result in a significant increase in shear strength against liquefaction. Recently, new interpretations of liquefaction phenomena in unsaturated conditions have been provided by [5] using an energetic approach, which is able to simulate the resistance to liquefaction of unsaturated sandy soils as reported by [6]. Nevertheless, few researches have been 


\section{Civil Engineering Research Journal}

performed to study how desaturate the soils and to apply in situ this effective mitigation technique. One of the most interesting techniques could be an induced desaturation by means of electrokinetic phenomena. Desaturation can be reached by introducing small amounts of gas through electrolysis. By lowering the degree of saturation from full saturation to about $90 \%$, for example, volumetric strain and pore pressure generation can be reduced by several times.

\section{Desaturation of Soil Deposits Through Electrolysis}

When an electric field is applied to the soil for some time through electrodes, electrokinetic phenomena are generated (electroosmosis, electromigration and electrophoresis). In particular, pore water is transported by electroosmosis through the porous medium and, at the same time, electrolysis of pore water occurs near the electrodes. This leads to the formation of ions at the cathode and ions at the anode, which are transported by the flow and by the electric field, and there is therefore a change of , that is not homogeneous in the porous medium. It means that electrolysis may be used to entrap gas molecules in saturated specimen. Electrokinetic treatments are increasingly being used in geotechnical and geoenvironmental engineering for site remediation and dewatering of clays [6-12]. Recently, [13] have explored the use of electrokinetics to grout soils for liquefaction mitigation applications. While the gas quantities produced by electrolysis are not high enough to produce any safety hazard (especially gas), they are significant enough to change the degree of saturation. Furthermore, the electrolysis process can generate, at least under laboratory conditions, a controlled amount of gases without disturbing the specimen [14].

Although the effectiveness of electrolysis to desaturate sandy soils has been investigated in laboratory [15], new tests can be useful to verify the effectiveness and the applicability in a bigger scale, realizing, for example, field trials in liquefiable areas. There have been limited studies investigating the practical considerations for field implementations and the factors affecting the process. In particular, some technical problems could hamper its application at the industrial scale. These problems include the electrode corrosion and high-power consumption [16]. Process parameters such as the timing of the electric field application, total energy input and energy input distribution in time will affect the desaturation results and overall the energy efficiency. Different operating conditions are possible, such as the use of inert electrodes like graphite and "pressed carboncoated" electrodes, in order to reduce the corrosion; or the use of intermittent current for the reduction of power consumption and electrode corrosion. This technique has several advantages, such as being less expensive (cost-effective), being applicable both in-situ and ex-situ, rapid installation and easy to operate (simplicity), having silent operation, having the advantage of not disturbing the site activities, and relatively short treatment duration [17-22]. It is also worth noting that electrolysis, apart from desaturation, could be extremely important also to remove polluting substances.

\section{Conclusion}

Liquefaction is one of the most critical issues for tailing dams in all parts of the world as demonstrated by several case histories. Sometimes, traditional mitigation techniques (such as densification or soil reinforcement) seem not to be easy to apply. Owing to that, new technologies have been investigated. In particular, desaturation is considered one of the most promising techniques. To desaturate soil deposits electrolysis may be used. Even though it is studied in small scale, demonstrating its effectiveness, new studies have to be performed to investigate its application in field.

\section{References}

1. Chaney R (1978) Saturation effects on the cyclic strength of sands Proc., ASCE Special Conf. on Earthquake Engineering and Soil Dynamics, New York, USA. pp. 342-358.

2. Yoshimi Y, Yanaka K, Tokimatsu K (1989) Liquefaction resistance of partially saturated sand. Soils Found 29(3): 157-162.

3. Okamura M, Soga Y (2006) Effects of pore fluid compressibility on liquefaction resistance of partially saturated sand. Soils and Foundations 46(5): 695-700.

4. Mele L, Tan Tian J, Lirer S, Flora A, Koseki J (2018) Liquefaction resistance of unsaturated sands: experimental evidence and theoretical interpretation.Géotechnique.

5. Mele L, Lirer S, Flora A (2019) A liquefaction surface to describe liquefaction phenomena in unsaturated sandy soils. $7^{\text {th }}$ International Conference on Earthquake Geotechnical Engineering, 7ICEGE, Rome (Italy).

6. Casagrande L (1949) Electro-osmosis in soils. Géotechnique 1(3): 159177.

7. Esrig MI (1968) Pore pressures, consolidation and electrokinetics. Journal of the Soil Mechanics and Foundations Division, ASCE 94(7): 899-922.

8. Flora A, Gargano S, Lirer S, Mele L (2016) Effect of Electro-kinetic consolidation on fine grained dredged sediments. Procedia Engineering 158: 3-8.

9. Flora A, Gargano S, Lirer S, Mele L (2017) Experimental Evidences of the Strengthening of Dredged Sediments by Electroosmotic Consolidation. Geotechnical and Geological Engineering 35(6): 2879-2890.

10. Gargano S, Lirer S, Flora A (2018) Analysis of the coupled electroosmotic and mechanical consolidation in clayey soils. Proceedings of the Institution of Civil Engineers - Ground Improvement.

11. Gargano S, Lirer S, Liguori B, and Flora A (2019) Experimental analysis of the effects of electrokinetic treatment of soils. E3S Web of Conferences 92(2019).

12. Gargano S, Lirer S, Flora A (2020) Mechanical and physical effects of electroosmotic dewatering of clayey soils. Geotechnical Research for Land Protection and Development. Lecture Notes in Civil Engineering, 40: 387-396.

13. Thevanayagam S, Jia W (2003) Electro-osmotic grouting for liquefaction mitigation in silty soils. ASCE Conf Proc Paper, Grouting and Ground Treatment, New Orleans. pp.1507-1517.

14. Bayat EE, Yegian MK, Alshawabkeh A, Gokyer S (2009) A new mitigation technique for preventing liquefaction-induced building damages 


\section{Civil Engineering Research Journal}

during earthquakes. WCCE-ECCE-TCCE Joint Conference: Earthquake \& Tsunami.

15. Yegian MK, Eseller-Bayat E, Alshawabkeh A, Ali S (2007) Inducedpartial saturation for liquefaction mitigation: experimental investigation. Journal of Geotechnical and Geoenvironmental Engineering 133(4): 372-380.

16. Raats MHM, Van Diemen AJG, Laven J, Stein HN (2002) Full scale electrokinetic dewatering of waste sludge. Colloids and Surfaces A-Physicochemical and Engineering Aspects 210(2-3): 231-241.

17. Aguero G (1929) Formacion de Depositos de Relaves en el Mineral del Teniente. Anales del Institute de Ingenieros de Chile 5: 164-187.

18. Dobry R, Alvarez L (1967) Seismic Failures of Chilean Tailings Dams. Proc. ASCE 93(6): 237-260.
19. Krishnaswamy NRIsaac NT (1994) Liquefaction potential of reinforced sand. Geotexiles and Geomembranes 13(1): 23-41.

20. Mele L, Flora A (2019) On the prediction of liquefaction resistance of unsaturated sands. Soil Dynamics and Earthquake Engineering 125.

21. Okusa S, Anrna S (1980) Slope Failures and Tailings Darn Damage in the 1978 IzuOhshima-Kinkai Earthquake. Engineering Geology, Elsevier Scientific Publishing Co. 16: 195-224.

22. Marcuson WF, Ballard RF, Ledbetter RH (1979) Liquefaction Failure of Tailings Dams Resulting from the Near Izu Ohshima Earthquake. $6^{\text {th }}$ Panamerican Conference on Soil Mechanics and Foundation Engineering, Lima 2: 69-80.

\section{Your next submission with Juniper Publishers will reach you the below assets}

- Quality Editorial service

- Swift Peer Review

- Reprints availability

- E-prints Service

- Manuscript Podcast for convenient understanding

- Global attainment for your research

- Manuscript accessibility in different formats

( Pdf, E-pub, Full Text, Audio)

- Unceasing customer service

Track the below URL for one-step submission https://juniperpublishers.com/online-submission.php 